\title{
Treatment of Benign Thyroid Nodules: Comparison of Surgery with Radiofrequency Ablation
}

\author{
Y. Che, S. Jin, C. Shi, L. Wang, X. Zhang, Y. Li, and J.H. Baek
}

\begin{abstract}
BACKGROUND AND PURPOSE: Nodular goiter is one of the most common benign lesions in thyroid nodule. The main treatment of the disease is still the traditional surgical resection, however there are many problems such as general anesthesia, surgical scar, postoperative thyroid or parathyroid function abnormalities, and high nodules recurrence rate in residual gland. The purpose of this study was to compare the efficacy, safety, and cost-effectiveness of 2 treatment methods, surgery and radiofrequency ablation, for the treatment of benign thyroid nodules.
\end{abstract}

MATERIALS AND METHODS: From May 2012 to September 2013, 200 patients with nodular goiters who underwent surgery (group A) and 200 patients treated by radiofrequency ablation (group B) were enrolled in this study. Inclusion criteria were the following: 1) cosmetic problem, 2) nodule-related symptoms, 3) hyperfunctioning nodules related to thyrotoxicosis, and 4) refusal of surgery (for group B). An internally cooled radiofrequency ablation system and an 18-ga internally cooled electrode were used. We compared the 2 groups in terms of efficacy, safety, and cost-effectiveness during a l-year follow-up.

RESULTS: After radiofrequency ablation, the nodule volume decreased significantly from 5.4 to $0.4 \mathrm{~mL}(P=.002)$ at the 12 -month follow-up. The incidence of complications was significantly higher from surgery than from radiofrequency ablation $(6.0 \%$ versus $1.0 \%, P=$ .002). Hypothyroidism was detected in $71.5 \%$ of patients after surgery but in none following radiofrequency ablation. The rate of residual nodules $(11.9 \%$ versus $2.9 \%, P=.004)$ and hospitalization days was significantly greater after surgery (6.6 versus 2.1 days, $P<.001)$, but the cost difference was not significant.

CONCLUSIONS: Surgical resection and radiofrequency ablation are both effective treatments of nodular goiter. Compared with surgery, the advantages of radiofrequency ablation include fewer complications, preservation of thyroid function, and fewer hospitalization days. Therefore, radiofrequency ablation should be considered a first-line treatment for benign thyroid nodules.

ABBREVIATIONS: RFA = radiofrequency ablation; US = ultrasound

T he incidence of nodular goiter has been gradually increasing in recent years, but its treatment has been controversial to date. ${ }^{1,2}$ Current guidelines suggest that a nodule without clinical symptoms should be treated with watchful waiting; however,

Received October 26, 2014; accepted after revision December 17

From the Departments of Ultrasound (Y.C., L.W., X.Z.), Laparoscopic Surgery (S.J.), and Pathology (C.S.), First Affiliated Hospital of Dalian Medical University, Dalian, China; Department of Radiology and Research Institute of Radiology (J.H.B.), University of Ulsan College of Medicine, Asan Medical Center, Seoul, Korea; and College of Basic Medical Sciences and Institute of Cancer Stem Cell (Y.L.), Dalian Medical University, Dalian, China.

Please address correspondence to Ying Che, MD, Department of Ultrasound, First Affiliated Hospital of Dalian Medical University, Dalian, Liaoning 116011, China; e-mail: yche1964@163.com; Jung Hwan Baek, MD, Department of Radiology and the Research Institute of Radiology, University of Ulsan College of Medicine, Asan Medical Center, 86 Asanbyeongwon-Gil, Songpa-Gu, Seoul 138-736, Korea; e-mail: radbaek@naver.com

Evidence-Based Medicine Level 2.

http://dx.doi.org/10.3174/ajnr.A4276 some patients require treatment because of cosmetic problems or symptoms. Some investigators also believe that even if the incidence of malignancy rate is as low as $5 \%-15 \%$, malignancy is still a concern. Thus, surgery has been advocated by some clinicians, but after resection of the nodules, patients often have neck scars or hypothyroidism, which seriously affects their quality of life. ${ }^{3,4}$ Additional issues include the risks of general anesthesia and postoperative parathyroid function abnormalities. ${ }^{1-3,5}$ Therefore, minimally invasive alternatives have been explored. Ethanol ablation, laser ablation, microwave ablation, and radiofrequency ablation (RFA) are safe and effective techniques for the treatment of nodular goiter. ${ }^{6-8}$ Ethanol ablation is useful in cystic nodules but not in solid nodules. Laser ablation, microwave ablation, and RFA are useful in different-sized nodules, respectively. ${ }^{9}$

Since Dupuy et $\mathrm{al}^{10}$ first pioneered the application of radiofrequency ablation to treat recurrent thyroid cancers, RFA has been widely used for the treatment of benign thyroid nodules, goiters, 
Table 1: Demographic characteristics of the experimental subjects

\begin{tabular}{lccc}
\hline & Surgery $(\boldsymbol{n}=\mathbf{2 0 0})$ & RFA $(\boldsymbol{n}=\mathbf{2 0 0})$ & $\boldsymbol{P}$ Value \\
\hline Mean age $(\mathrm{yr})$ (range) & $52.4 \pm 13.9(23-78)$ & $43.8 \pm 12.7(15-84)$ & .76 \\
Sex (M/F) & $46: 154$ & $35: 165$ & .89 \\
Index nodules & 403 & 375 & \\
$\quad$ Mean diameter $(\mathrm{cm})$ & $4.1 \pm 3.2$ & $3.4 \pm 3.7$ & .79 \\
Mean volume $(\mathrm{mL})$ & $5.9 \pm 6.4$ & $5.4 \pm 7.1$ & .88 \\
No. of nodules (single/multiple) & $49: 151$ & $62: 138$ & .147 \\
\hline
\end{tabular}

\begin{tabular}{|c|c|c|c|c|}
\hline Period & $\begin{array}{l}\text { No. of } \\
\text { Nodules }\end{array}$ & $\begin{array}{c}\text { Mean } \\
\text { Volume }(\mathrm{mL})\end{array}$ & $\begin{array}{l}\% \text { Volume } \\
\text { Reduction }^{a}\end{array}$ & $\begin{array}{c}P \\
\text { Value }^{\mathrm{b}}\end{array}$ \\
\hline Before treatment & 375 & $5.4 \pm 7.1$ & & \\
\hline $1 \mathrm{mo}$ & 375 & $3.1 \pm 4.4$ & $37.5 \pm 43.4$ & .030 \\
\hline $3 \mathrm{mo}$ & 301 & $2.1 \pm 3.0$ & $61.3 \pm 37.6$ & .025 \\
\hline $6 \mathrm{mo}$ & 247 & $1.2 \pm 1.9$ & $74.6 \pm 23.3$ & .009 \\
\hline $12 \mathrm{mo}$ & 194 & $0.4 \pm 0.7$ & $84.8 \pm 17.1$ & .002 \\
\hline
\end{tabular}

a Note that "\% Volume Reduction" represents the proportion of residual volume compared with the index nodule volume.

${ }^{\mathrm{b}} \mathrm{P}$ value represents a comparison of before treatment with each follow-up assessment.

and recurrent thyroid cancers. ${ }^{11-15}$ Recently, many studies including long-term follow-up studies, ${ }^{16}$ randomized controlled trials, ${ }^{6,17}$ and a meta-analysis ${ }^{18}$ have promulgated the efficacy and safety of RFA. To date, however, only 1 study has compared surgery and RFA, ${ }^{13}$ and it enrolled a relatively small population of 37 patients treated with RFA and 74 patients treated with surgery. The purpose of this study was to compare the efficacy, safety, and cost-effectiveness of 2 treatment methods, surgery and RFA, in a large population treated for benign thyroid nodules.

\section{MATERIALS AND METHODS \\ Patients}

This retrospective study was approved by the institutional review board at the First Affiliated Hospital of Dalian Medical University, and informed consent was obtained from all patients before surgery or RFA. From May 2012 to September 2013, 200 patients with nodular goiter who underwent surgery (group A) and 200 patients treated with sonography (US)-guided RFA (group B) were enrolled in this study. The surgery group was diagnosed as having a nodular goiter by surgical pathology, and the RFA group was diagnosed cytologically from 2 preoperative fine-needle aspirates. ${ }^{19,20}$ All the enrolled patients fulfilled the following criteria according to the RFA recommendations of the Korean Society of Thyroid Radiology ${ }^{21}:$ 1) having a cosmetic problem, 2) having nodule-related symptoms, 3) having hyperfunctioning nodules related to thyrotoxicosis, and 4) having refused surgery. Patients without complete surgical and/or follow-up information were excluded.

\section{Devices and Procedures}

We used a HI VISION Preirus system (Hitachi Medical System, Tokyo, Japan) with a 10-MHz linear probe, internally cooled RFA system (VIVA RF generator; STARmed, Gyeonggi, Korea) with an 18-ga internally cooled electrode (VIVA; STARmed) during the US, US-guided biopsy, and RFA. Laboratory examinations included preoperative thyroid function and coagulation tests. US examination evaluated the location, size, and vascularity of the nodules to design the treatment plan. The patients in group A underwent surgery under general anesthesia. Surgery was performed by general surgeons with $>8$ years' clinical experience. The surgery methods included total thyroidectomy and lobectomy according to the guidelines of the National Comprehensive Cancer Network. ${ }^{22}$

In group B patients, local anesthetic with $2 \%$ lidocaine was used to control pain. RFA was performed by 1 radiologist (Y.C. with 7 years' clinical experience and 2 years' RFA experience) by using previously described standard RFA techniques such as transisthmic approach methods and a "moving-shot" technique. ${ }^{14,21,23}$ The procedure was finished when an entire nodule changed to a no-enhancement zone by real-time US examination with contrast (sulphur hexafluoride microbubbles for injection, SonoVue; Bracco Suisse SA, Plan-Les-Ouates, Switzerland). The 2 groups of patients underwent a US check at 1, 6, and 12 months after treatment. In group A, an examination of thyroid function was performed to adjust the optimal dosage of levothyroxine (Euthyrox) 1 month after the thyroid resection. In group B, thyroid function was examined 1 week after RFA. If any functional anomalies were demonstrated, thyroid function was evaluated every month until normalization.

Surgical complications were monitored immediately after thyroid surgery and during the follow-up period. ${ }^{4}$ The complications of RFA were checked during and after treatment according to the definitions of the Society of Interventional Radiology. ${ }^{24,25}$ The changes in nodule volumes were evaluated before and during the follow-up periods. "Residual" was defined as a certain part of single or multiple nodules that is not completely inactivated. The residual rate was defined as the rate of the number of people who had residual goiter divided by the total number. Recurrence was defined as the regrowth of thyroid tissue after treatment according to the definition of a previous study. ${ }^{16}$ The cost was the total of hospitalization, clinical tests, and surgery costs.

\section{Statistical Methods}

SPSS (Version 11.5; IBM, Armonk, New York) statistical software was used to analyze the data. Data measurements were expressed as mean \pm SD and range. Comparison of the 2 groups was done by the Wilcoxon signed rank test. The threshold for statistically significant differences was defined as $P<.05$.

\section{RESULTS}

Table 1 summarizes a comparison of demographic data of the 2 groups. No demographic data differed significantly between the 2 groups before treatment, including the mean patient age, sex, nodule size, or nodule numbers.

\section{Efficacy}

Changes in nodule volume and percentage volume reduction before and after RFA are shown in Table 2, and a representative RFA patient case is described in the Figure. The mean volume of the index nodules was $5.4 \pm 7.1 \mathrm{~mL}$ (range, $0.3-47.1 \mathrm{~mL}$ ). The nodule volume at 12 -month follow-up had decreased significantly from 

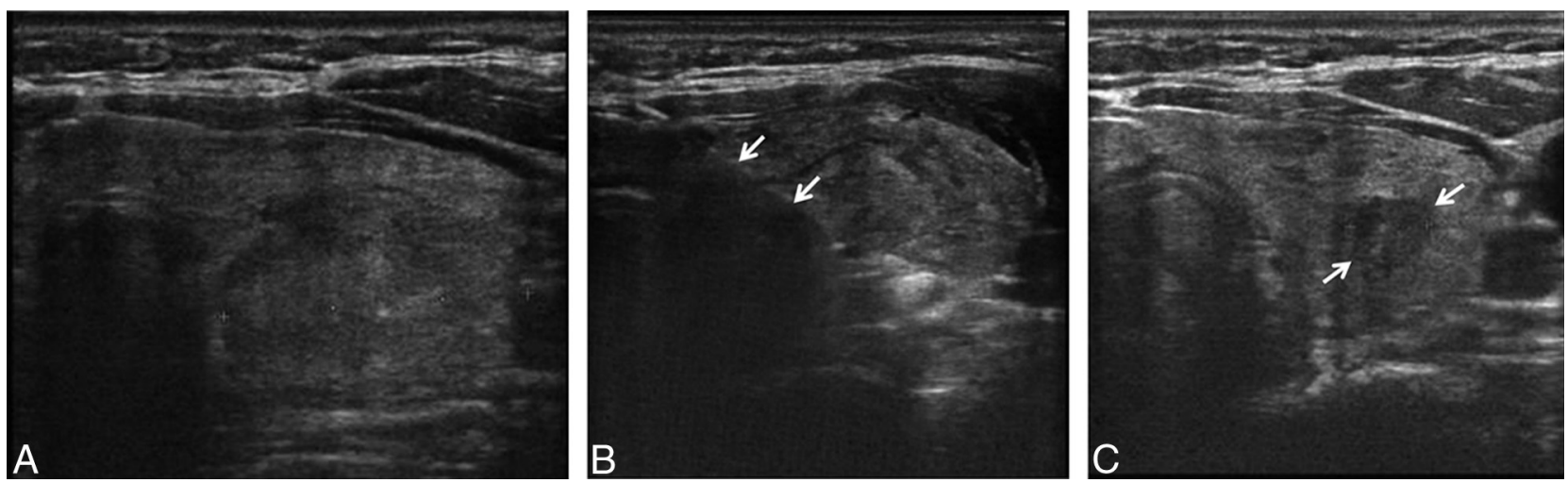

FIGURE. A 50-year-old woman with left-neck discomfort. A, Before treatment, a 3-cm solid, left thyroid nodule is evident. B, During the RF ablation, the electrode (arrows) is placed within the nodule. $C$, Six months after RF ablation, the treated nodule (arrows) has decreased considerably in size and measures only $8 \mathrm{~mm}$.

Table 3: Overall comparison of surgery versus RFA

\begin{tabular}{lccc} 
& Surgery $(\boldsymbol{n}=\mathbf{2 0 0})$ & RFA $(\boldsymbol{n}=\mathbf{2 0 0})$ & $\boldsymbol{P}$ Value \\
\hline Residue $^{\mathrm{a}}$ & $11.9 \%$ & $2.9 \%$ & .004 \\
Recurrence $^{\mathrm{b}}$ & $2.5 \%$ & $0.05 \%$ & .100 \\
Complications & $6 \%$ & $1 \%$ & .002 \\
Postoperative medication & $71.5 \%$ & 0 & .002 \\
Mean hospitalization (days) & $6.6 \pm 1.6$ & $2.1 \pm 0.9$ & .000 \\
Cost (Chinese yuan) (US dollars) & $¥ 15,962 \pm ¥ 1073$ & $¥ 16,535 \pm ¥ 2309$ & .99 \\
& $(\$ 2556.95 \pm \$ 171.88)$ & $(\$ 2648.74 \pm \$ 369.88)$ & \\
\hline
\end{tabular}

a "Residue" is defined as no complicated treatment in single or multiple nodules.

b "Recurrence" is defined as the appearance of a new goiter after treatment.

Table 4: Complications observed following surgery versus RFA ${ }^{a}$

\begin{tabular}{lcc}
\hline & Surgery $(\boldsymbol{n}=\mathbf{2 0 0})$ & RFA $(\boldsymbol{n}=\mathbf{2 0 0})$ \\
\hline Hoarseness & & \\
Transient & 3 & 1 \\
Permanent & 2 & 0 \\
Hypoparathyroidism transient & 6 & 0 \\
Hematoma & 1 & 0 \\
Nodule rupture & 0 & 1 \\
Total & 12 & 2 \\
\hline
\end{tabular}

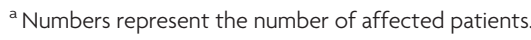

$5.4 \pm 7.1 \mathrm{~mL}$ to $0.4 \pm 0.7 \mathrm{~mL}(P=.002)$, and the percentage volume reduction was $84.8 \pm 17.1 \%$ (range, $61.3 \%-100 \%$ ). Table 3 shows the results and complications of the 2 groups. The residual rate in the surgery group was significantly higher than that in the RFA group ( $11.9 \%$ versus $2.9 \%, P=.004)$.

\section{Safety}

The number of patients with complications in the 2 groups is described in Table 4. The overall complication rate in the surgery group was significantly higher than that of the RFA group $(6 \%$ versus $1 \%, P=.002$ ). Transient hoarseness was reported in 3 patients after surgery versus 1 patient after RFA, but they recovered completely during the follow-up of 1-3 months. Two patients with a permanent unilateral recurrent laryngeal nerve injury were reported only in the surgery group. Six patients with transient hypoparathyroidism were reported in the surgery group and recovered in 3-7 days after surgery. Nodule rupture was reported in 1 patient 1 week after RFA; however, he recovered without any treatment within 2 weeks.

Regarding thyroid function and medication, the surgery group showed a significantly higher postoperative medication rate than the RFA group $(71.5 \%$ versus $0 \%, P=.002)$. In the surgery group, $71.5 \%$ of patients showed postoperative hypothyroidism that required daily supplemental exogenous thyroid hormone (Euthyrox). Approximately $42 \%$ of those patients needed $50 \mu \mathrm{g} /$ day of hormone, $4 \%$ needed $75 \mu \mathrm{g} /$ day, and $25.5 \%$ needed $100 \mu \mathrm{g} /$ day. In the RFA group, $93 \%$ of patients had normal levels of T3, T4, and thyroid-stimulating hormone. Only $7 \%$ of patients showed a decreased thyroid-stimulating hormone without an elevation in T3 or T4 while also having no hyperthyroid symptoms. The patients recovered spontaneously from these conditions by their 1-month follow-up.

\section{Cost Effectiveness}

The mean hospitalization stay was significantly longer in the surgery group ( $6.6 \pm 1.6$ days versus $2.1 \pm 0.9$ days, $P=.00$ ). The total cost between the 2 groups was not significantly different $(P=.99)$; the cost of surgery was $¥ 15,962 \pm ¥ 1073$ (Chinese yuan) $(\$ 2556.95 \pm \$ 171.88)$ and that of RFA was $¥ 16,535 \pm ¥ 2309$ (\$2648.74 $\pm \$ 369.88)$.

\section{DISCUSSION}

Our large-population study comparing surgery and RFA for the management of benign thyroid nodules demonstrated that RFA effectively decreases thyroid nodule volume $(84.8 \%$ volume reduction at 1-year follow-up), and the recurrence rate after RFA treatment was similar to that of surgery. The complication rate was significantly lower after RFA than following surgery (6\% versus $1 \%, P=.002)$. In addition, thyroid function after RFA treatment is well-maintained but is decreased in $71.5 \%$ of patients after surgery. The cost of RFA was found to be similar to that of surgery, and clinical recovery was faster and easier on the patient; additionally, no external scar was present.

RFA of benign thyroid nodules had a demonstrated efficacy and safety in previous studies, ${ }^{16,26,27}$ and the volume reduction reported is approximately $84 \%-90 \%$ at 1 -year follow-up. ${ }^{14,16,28}$ We observed a similar volume reduction of $84.8 \%$ in our study. Because of the complexity of the thyroid and neck anatomy, 
surgery has a high incidence of complications such as recurrent laryngeal nerve injury, hypoparathyroidism, and hypothyroidism $^{3,4,29,30}$; however, the complication rate reported for RFA was low in the study by Baek et al, ${ }^{25}$ a $3.3 \%$ complication rate with thyroid RFA in their multicenter study. In our current study, the RFA complication rate was found to be lower than that of surgery. Recurrent laryngeal nerve injury occurred in 3.0\% of our surgery group versus $0.5 \%$ for our RFA group. RFA can minimize the nerve injury rate because real-time US imaging allows the radiologist to monitor the dangerous triangle in which the recurrent laryngeal nerve is located, ${ }^{25,31}$ and hydrodissection has been introduced as a safe technique to prevent thermal damage to the nerve. $^{32,33}$ The rate of hypoparathyroidism was 3.0\% in our surgery group but was totally absent from our RFA group. This difference is caused by the varied position of the parathyroid gland and low resolution during the operation. During RFA, parathyroid injury has not yet been reported. Hematoma was also reported only in our surgery group. Baek et $\mathrm{al}^{25}$ reported that approximately $1 \%$ of patients developed a hematoma in their large-population multicenter study. During RFA, a hemorrhage can be detected by real-time US and easily controlled by manual compression. Hypothyroidism affected $71.5 \%$ of our surgery group but none of our patients undergoing RFA. Baek et $\mathrm{al}^{25}$ reported only $0.07 \%$ (1/1459) hypothyroidism after thyroid RFA. Hypothyroidism is a rare complication in thyroid RFA because RFA minimizes the chance of injury to the normal thyroid. In our RFA group, 1 patient initially experienced thyroid nodule rupture 1 week after the RFA, but this complication resolved spontaneously in 2 weeks without the need for taking antibiotics. Previous studies suggest that patients with nodule rupture should be treated conservatively rather than with an intervention. ${ }^{25}$ Our results demonstrate a lower complication rate for RFA than for surgery, which is similar to the findings of Bernardi et al. ${ }^{13}$

In nodular goiter, most of the nodules arise in multiples. Therefore, resection of a large volume of the normal glandular tissue is the main cause of hypothyroidism. In our present study, $71.5 \%$ of patients showed a decreased level of serum thyroid hormone after surgery, which requires life-long exogenous thyroid hormone replacement therapy. By its nature, surgery removes the goiters and some surrounding normal thyroid tissue; however, RFA only ablates the goiter and spares most normal tissue. Therefore, thyroid function is better protected by an RFA approach.

Compared with the results of Bernardi et $a l,{ }^{13}$ our current study shows the advantages of RFA in a large population. We also analyzed the detailed comparison of 2 procedures in terms of the duration of the hospital stay, residual disease, and the recurrence rate, in addition to complications and thyroid function. In our analyses, the mean hospitalization days were significantly fewer in the RFA group $(6.6 \pm 1.6$ days versus $2.1 \pm 0.9$ days, $P<.001)$ and residual thyroid nodules were also less frequent after RFA than surgery. RFA minimizes normal thyroid tissue injury because the radiofrequency electrode moves only within the nodule. ${ }^{9,14,21}$ Therefore, damage to thyroid function is rare, and few residual nodules remain after RFA. RFA showed a low recurrence rate after treatment in our patients, which is con- sistent with published recurrence rates after RFA of 5.6\% during follow-up of 4 years. ${ }^{16}$

A neck scar resulting from surgery can also be a concern to patients. Although performing thyroid surgery by laparoscope has a benefit of less neck scarring, other skin, such as the axillary and anterior chest, will still scar. ${ }^{34}$ RFA is a percutaneous, minimally invasive procedure under US monitoring. Because the outer diameter of the electrode is $1.2 \mathrm{~mm}$, the RFA-related wound is tiny and patients fully recover in a few weeks. Most patients can be treated on an outpatient basis and can leave the hospital 1-2 hours after RFA without any disturbance in daily activities. The costs of RFA are comparable with those of conventional surgery in China. In nearly all respects, RFA shows superior performance to surgery for the treatment of thyroid nodules.

A limitation of our study was the short follow-up and the retrospective design. However, residual nodules and recurrence are rare on the basis of previous reports. We hope our results may motivate others to perform more extensive prospective studies to assess the effectiveness of this alternative approach.

\section{CONCLUSIONS}

RFA of a benign thyroid nodule effectively treats with a low incidence of complications, no effects on thyroid or parathyroid function, low nodular recurrence rate, and shorter hospitalization periods. Hence, RFA should be considered as possibly the first-line treatment for benign thyroid nodules.

\section{REFERENCES}

1. Cooper DS, Doherty GM, Haugen BR, et al. Revised American Thyroid Association management guidelines for patients with thyroid nodules and differentiated thyroid cancer. Thyroid 2009;19: $1167-214$

2. Gharib H, Papini E, Paschke R, et al. American Association of Clinical Endocrinologists, Associazione Medici Endocrinologi, and EuropeanThyroid Association Medical Guidelines for Clinical Practice for the Diagnosis and Management of Thyroid Nodules. Endocr Pract 2010;16(suppl 1):1-43

3. Gibelin H, Sierra M, Mothes D, et al. Risk factors for recurrent nodular goiter after thyroidectomy for benign disease: case-control study of 244 patients. World J Surg 2004;28:1079-82

4. Pelizzo MR, Merante Boschin I, Toniato A, et al. Surgical therapeutic planning options in nodular goiter. Minerva Endocrinol 2010;35: 173-85

5. Roh JL, Park JY, Park CI. Total thyroidectomy plus neck dissection in differentiated papillary thyroid carcinoma patients: pattern of nodal metastasis, morbidity, recurrence, and postoperative levels of serum parathyroid hormone. Ann Surg 2007;245:604-10

6. Sung JY, Baek JH, Kim KS, et al. Single-session treatment of benign cystic thyroid nodules with ethanol versus radiofrequency ablation: a prospective randomized study. Radiology 2013;269:293-300

7. Papini E, Rago T, Gambelunghe G, et al. Long-term efficacy of ultrasound-guided laser ablation for benign solid thyroid nodules: results of a three-year multicenter prospective randomized trial. J Clin Endocrinol Metab 2014;99:3653-59

8. Feng B, Liang P, Cheng Z, et al. Ultrasound-guided percutaneous microwave ablation of benign thyroid nodules: experimental and clinical studies. Eur J Endocrinol 2012;166:1031-37

9. Ha EJ, Baek JH. Advances in nonsurgical treatment of benign thyroid nodules. Future Oncol 2014;10:1399-405

10. Dupuy DE, Monchik JM, Decrea C, et al. Radiofrequency ablation of regional recurrence from well-differentiated thyroid malignancy. Surgery 2001;130:971-77 
11. Baek JH, Kim YS, Sung JY, et al. Locoregional control of metastatic well-differentiated thyroid cancer by ultrasound-guided radiofrequency ablation. AJR Am J Roentgenol 2011;197:W331-36

12. Baek JH, Moon WJ, Kim YS, et al. Radiofrequency ablation for the treatment of autonomously functioning thyroid nodules. World J Surg 2009;33:1971-77

13. Bernardi S, Dobrinja C, Fabris B, et al. Radiofrequency ablation compared to surgery for the treatment of benign thyroid nodules. Int J Endocrinol 2014;2014:934595

14. Jeong WK, Baek JH, Rhim H, et al. Radiofrequency ablation of benign thyroid nodules: safety and imaging follow-up in 236 patients. Eur Radiol 2008;18:1244-50

15. Shin JH, Baek JH, Oh YM, et al. Combination therapy of temporary tracheal stenting and radiofrequency ablation for multinodular thyroid goiter with airway compression. Korean J Radiol 2013; 14:805-09

16. Lim HK, Lee JH, Ha EJ, et al. Radiofrequency ablation of benign non-functioning thyroid nodules: 4-year follow-up results for 111 patients. Eur Radiol 2013;23:1044-49

17. Faggiano A, Ramundo V, Assanti AP, et al. Thyroid nodules treated with percutaneous radiofrequency thermal ablation: a comparative study. J Clin Endocrinol Metab 2012;97:4439-45

18. Fuller CW, Nguyen SA, Lohia S, et al. Radiofrequency ablation for treatment of benign thyroid nodules: systematic review. Laryngoscope 2014;124:346-53

19. Kwak JY, Jung I, Baek JH, et al; Korean Society of Thyroid Radiology (KSThR); Korean Society of Radiology. Image reporting and characterization system for ultrasound features of thyroid nodules: multicentric Korean retrospective study. Korean J Radiol 2013;14: $110-17$

20. Moon WJ, Baek JH, Jung SL, et al; Korean Society of Thyroid Radiology (KSThR); Korean Society of Radiology. Ultrasonography and the ultrasound-based management of thyroid nodules: consensus statement and recommendations. Korean J Radiol 2011;12:1-14

21. Na DG, Lee JH, Jung SL, et al; Korean Society of Thyroid Radiology (KSThR); Korean Society of Radiology. Radiofrequency ablation of benign thyroid nodules and recurrent thyroid cancers: consensus statement and recommendations. Korean J Radiol 2012;13:117-25

22. Urken ML, Milas M, Randolph GW, et al. Management of recurrent and persistent metastatic lymph nodes in well-differentiated thy- roid cancer: a multifactorial decision-making guide for the thyroid cancer care collaborative. Head Neck 2015;37:605-14

23. Ha EJ, Baek JH, Lee JH. Moving-shot versus fixed electrode techniques used for radiofrequency ablation: an experimental comparison in an ex-vivo bovine liver tissue model. Korean J Radiol 2014;15:836-43

24. Burke DR, Lewis CA, Cardella JF, et al. Quality improvement guidelines for percutaneous transhepatic cholangiography and biliary drainage. J Vasc Interv Radiol 2003;14:S243-46

25. Baek JH, Lee JH, Sung JY, et al. Complications encountered in the treatment of benign thyroid nodules with US-guided radiofrequency ablation: a multicenter study. Radiology 2012;262:335-42

26. Gharib H, Hegedus L, Pacella CM, et al. Clinical review: nonsurgical, image-guided, minimally invasive therapy for thyroid nodules. J Clin Endocrinol Metab 2013;98:3949-57

27. Papini E, Pacella CM, Hegedus L. Diagnosis of endocrine disease: thyroid ultrasound (US) and US-assisted procedures: from the shadows into an array of applications. Eur J Endocrinol 2014; 170:R133-46

28. Spiezia S, Garberoglio R, Milone F, et al. Thyroid nodules and related symptoms are stably controlled two years after radiofrequency thermal ablation. Thyroid 2009;19:219-25

29. Hayward NJ, Grodski S, Yeung M, et al. Recurrent laryngeal nerve injury in thyroid surgery: a review. ANZ J Surg 2013;83:15-21

30. Sun GH, Peress L, Pynnonen MA. Systematic review and meta-analysis of robotic vs conventional thyroidectomy approaches for thyroid disease. Otolaryngol Head Neck Surg 2014;150:520-32

31. Shin JH, Baek JH, Ha EJ, et al. Radiofrequency ablation of thyroid nodules: basic principles and clinical application. Int J Endocrinol 2012;2012:919650

32. Lim HK, Baek JH, Lee JH, et al. Efficacy and safety of radiofrequency ablation for treating locoregional recurrence from papillary thyroid cancer. Eur Radiol 2015;25:163-70

33. Shin JE, Baek JH, Lee JH. Radiofrequency and ethanol ablation for the treatment of recurrent thyroid cancers: current status and challenges. Curr Opin Oncol 2013;25:14-19

34. Lee KE, Kim HY, Park WS, et al. Postauricular and axillary approach endoscopic neck surgery: a new technique. World J Surg 2009;33: 767-72 